\title{
Arsenic Adsorption by Some Iron Oxide Minerals: Influence of Interfacial Chemistry*
}

\author{
${ }^{1}$ B. Koomson and ${ }^{1}$ E. K. Asiam \\ ${ }^{1}$ Kwame Nkrumah University of Science and Technology, Kumasi, Ghana
}

Koomson, B. and Asiam, E. K. and (2020), "Arsenic Adsorption by Some Iron Oxide Minerals: Influence of Interfacial Chemistry”, Ghana Mining Journal, Vol. 20, No. 2, pp. 43-48.

\begin{abstract}
The dramatic increase in hydrometallurgical extraction of gold from arsenic bearing gold ores has inevitably resulted in the release of arsenic into the environment worldwide. Residual arsenic minerals in tailings storage facilities can be oxidised and mobilise arsenic into the environment. This can contaminate soils, ground and surface waters and eventually biota. In spite of well-established technologies and recent advances in arsenic remediation, there are limited knowledge and understanding of the iron oxide substrate (goethite, hematite and magnetite) mineralogy and the fate of arsenic on the surface charge of these iron oxide substrates in an aqueous media during adsorption. The aim of the present study was to investigate the influence of interfacial chemistry on arsenic adsorption onto selected iron oxide particles to assist in developing a better understanding and new knowledge in arsenic removal from contaminated waters. Bulk mineralogy and partial chemical composition of selected iron oxide minerals were obtained using quantitative $\mathrm{x}$-ray diffractometry (QXRD) and acid digestion followed by metal determination using inductively coupled plasma optical emission spectrometry (ICP-OES) respectively. Zeta Potential measurements involving iron oxide particles as arsenic adsorbents were carried out to elucidate the influence of interfacial chemistry on the adsorption behavior of arsenic from solution. The study confirmed that the iron oxide minerals were predominantly hematite, magnetite and goethite with goethite containing significant amounts of quartz. Arsenic adsorption was $\mathrm{pH}$ dependent and strongly influenced the zeta potential and isoelectric point (IEP) of the iron oxide particles. The zeta potential of all substrates studied was strongly positive at $\mathrm{pH} 2$ but indicated a reversal at $\mathrm{pH} \sim>9$. The interaction between substrates, arsenic and its hydrolysable products resulted in significant decrease in the magnitude of zeta potential and change in IEP indicating specific adsorption.
\end{abstract}

Keywords: Arsenic, Adsorption, Iron Oxide Minerals, Zeta Potential

\section{Introduction}

Arsenic can be introduced into the geo-environment because of the weathering of arsenic bearing minerals. For instance, refractory ores must be pretreated to decompose the sulphide minerals for effective recovery. However, residual undecomposed material in the tailings can weather to mobilise heavy metals into the geo-environment (Warhurst and Noronha, 2000; Fan et al., 2016). Arsenopyrite oxidation involves iron, sulphur and arsenic. It has been shown via activation energies that arsenopyrite oxidation occurs through surface reactions (Lengke, and Tempel, 2005). Therefore, in the presence of oxygenated water arsenic is released from the arsenopyrite as As (V) or metastable As (III). In arsenopyrites, Craw et al., (2003) and Walker et al., (2006) suggest that As(1-) and As(0) oxidise to As(III) at $\mathrm{pH} 4-9$ as shown in Equations 1 and 2 respectively.

$$
\begin{aligned}
\mathrm{FeAsS}+7 \mathrm{H}_{2} \mathrm{O} \rightarrow & \mathrm{Fe}^{2+}+\mathrm{H}_{3} \mathrm{AsO}_{3}^{\mathrm{o}}+11 \mathrm{H}^{+} \\
& +\mathrm{SO}_{4}^{2-} \\
4 \mathrm{FeAsS}+11 \mathrm{O}_{2}+ & 6 \mathrm{H}_{2} \mathrm{O} \\
& \rightarrow 4 \mathrm{Fe}^{2+}+4 \mathrm{H}_{3} \mathrm{AsO}_{3}^{\mathrm{o}} \\
& +4 \mathrm{SO}_{4}^{2-}
\end{aligned}
$$

Furthermore, during the bio-oxidation of auriferous sulphides, arsenic laden effluent is normally neutralised and deposited in tailings dams. The seepage from sulphide waste rocks and the precipitated arsenic materials in tailings dams can be mobilized into the geo-environment. Thus, it is important to remediate arsenic migration into the environment.

Several authors have demonstrated the usefulness of iron oxides as good adsorbents for arsenic remediation from water (Raven et al., 1998; Dixit and Hering, 2003; Yavuz et al., 2006; Giménez et al., 2007; Shipley et al., 2009; Koomson and Asiam, 2013). Arsenic (V) adsorption capacity of $37.3 \mathrm{mg} / \mathrm{g}$ by goethite (Faria et al., 2014), $46.06 \mathrm{mg} / \mathrm{g}$ by magnetite (Feng et al., 2012) and $95 \mathrm{mg} / \mathrm{g}$ by hematite (Prucek et al., 2013) have been reported in the literature. However, there is limited knowledge and understanding of the iron oxide substrate mineralogy and the fate of arsenic on the surface charge of the substrate in an aqueous media during adsorption. Obtaining an in-depth understanding of the substrate mineralogy and the fate of arsenic on the substrate's surface charge during adsorption will assist in the long-term storage and management of the substrates after adsorption. Hence, this is the focus of the study.

\section{Resources and Methods Used}

\subsection{Materials}

In this research, three different types of iron oxide minerals (goethite, hematite and magnetite) were 
used for the investigations. The iron oxide minerals: goethite, hematite and magnetite were obtained from Wards natural science (geology study pack), Hibbing, Minnesota, USA, Australia Bulk Minerals, Adelaide, Australia and Arrium Mining and Materials, Australia, respectively. Samples were used as received.

All chemical reagents used in the investigation were of analytical grade and obtained directly from commercial suppliers. Potassium hydroxide and nitric acid were used to control $\mathrm{pH}$ whilst potassium nitrate was used to control the ionic strength in the adsorption experiments. Arsenic (V) stock solution was obtained from Adelab Scientific, Australia.

\subsection{Methods}

\subsubsection{Materials Characterisation}

Bulk mineralogy of iron oxide minerals used in this work was determined by using quantitative $\mathrm{x}$-ray diffractometry (QXRD; Phillips PW 1050 X-ray generator equipped with Sietronic automated data collection). The specific surface area of the mineral particles was analysed by using Brunauer, Emmett and Teller (BET) method (Brunauer et al., 1938). The Gemini VII 2390 (Micrometrics, USA) was used. Partial chemical analysis of the minerals was determined using acid digestion. A known mass of each sample (3 $\mathrm{g}$ of $-75 \mu \mathrm{m})$ was digested and refluxed with a mixture of acids including hydrofluoric, nitric, perchloric and hydrochloric acid. Elements in supernatant solutions were then analysed using inductively coupled plasma optical emission spectrometry (ICP-OES; Perkin Elmer 5300 DV).

\subsubsection{Comminution}

The as received iron oxide minerals were wet milled for 20 mins each by using a rod mill with a solid loading of $1864 \mathrm{~g}$ (1000 g mineral and $864 \mathrm{~g}$ mill rods) and $1 \mathrm{~L}$ de-ionised water to obtain a particle size range of $80 \%$ passing $10 \mu \mathrm{m}$ required for zeta potential measurements. As a precaution to prevent contamination, stainless steel coated milling rods were used in this study.

\subsubsection{Zeta Potential Measurement}

Zeta potential measurements were conducted to investigate and ascertain the effect of arsenic adsorption on the surface charge of the iron oxide minerals. In this work, the mineral particle zeta potential was determined from dynamic mobility measurement using an acoustosizer (Acoustosizer II, Colloidal Dynamics, Inc, Australia).

Zeta potential measurements were conducted on 8 $\mathrm{wt} \%(280 \mathrm{ml})$ agitated suspensions of goethite, hematite and magnetite particles dispersed in $1 \times 10^{-3} \mathrm{M} \mathrm{KNO}^{3}$. The $1 \times 10^{-3} \mathrm{M} \mathrm{KNO}_{3}$ background electrolyte was used to avoid the effects of anomalous surface conductance on the mineral particle surface chemistry prior to arsenic adsorption. Agitation rates between 400 and 1800 rpm were employed. The experiment was conducted at room temperature and the $\mathrm{pH}$ was continually monitored in situ using probes, attached to the instrument. Prior to the zeta potential measurements, the suspensions were conditioned for $1 \mathrm{~h}$ to ensure even and adequate particle dispersion. During measurements, the suspensions were also allowed to equilibrate at an interval of $5 \mathrm{~min}$ before subsequent $\mathrm{pH}$ and zeta potential measurements were taken to ensure accurate results.

The $\mathrm{pH}$ at which the zeta potential of a mineral particle's surface is zero is known as its isoelectric point (IEP). The IEP is dependent on a number of factors including sample origin/mineralogy, type of electrolyte background used, measurement procedure employed and whether some other chemical specie(s) is being adsorbed unto the mineral particle's surface.

To be able to explain the changes in the surface chemistry of goethite, hematite and magnetite during As adsorption, an indifferent background electrolyte $\left(1 \times 10^{-3} \mathrm{M} \mathrm{KNO}_{3}\right)$ was first used for the zeta potential analysis to ascertain the initial IEP and zeta potential magnitude of the mineral surface. Afterward, a concentration of $20 \mathrm{ppm}\left(2.67 \times 10^{-4}\right.$ M) arsenic was then introduced and the zeta potential was measured to enhance the identification of any changes in the interfacial properties of the mineral surface used.

Before all measurements, the acoustosizer was calibrated using dissolved potassium tungstosilicate $\left(\mathrm{K}_{4}\left(\mathrm{SiW}_{12} \mathrm{O}_{40}\right)\right.$ salt as a calibration standard. This was used because it has very high chemical stability and provides a very strong electroacoustic signal.

\section{Results and Discussion}

\subsection{Mineralogical and Chemical Charac- teristics of Iron Oxide Minerals}

Results of the mineralogical and partial chemical composition of the iron oxide minerals are presented in Tables 1 and 2. 
Table 1 Mineralogical Composition of Iron Oxide Minerals Applied in the Adsorption Process

\begin{tabular}{|c|c|}
\hline \multicolumn{2}{|l|}{ A. Goethite } \\
\hline Compound Name & $\begin{array}{c}\text { Composition } \\
\text { (wt\%) }\end{array}$ \\
\hline Iron oxide hydroxide $(\mathrm{FeOOH})$ & 51 \\
\hline Silicon oxide $\left(\mathrm{SiO}_{2}\right)$ & 34 \\
\hline Iron oxide $\left(\mathrm{Fe}_{2} \mathrm{O}_{3}\right)$ & 12 \\
\hline $\begin{array}{l}\text { Potassium, manganese, oxide } \\
\text { hydrate }\left(\mathrm{K}_{0.3} \mathrm{Mn}_{0.9} \mathrm{O}_{2}\right)\left(\mathrm{H}_{2} \mathrm{O}\right)_{0.4}\end{array}$ & 3 \\
\hline Total & $\sim 100$ \\
\hline \multicolumn{2}{|l|}{ B. Hematite } \\
\hline Compound Name & $\begin{array}{l}\text { Composition } \\
(w t \%)\end{array}$ \\
\hline Iron Oxide $\left(\mathrm{Fe}_{2} \mathrm{O}_{3}\right)$ & 100 \\
\hline Total & $\sim 100$ \\
\hline \multicolumn{2}{|l|}{ C. Magnetite } \\
\hline Compound Name & $\begin{array}{c}\text { Composition } \\
(w t \%)\end{array}$ \\
\hline Iron oxide $\left(\mathrm{Fe}_{3} \mathrm{O}_{4}\right)$ & 82 \\
\hline Iron oxide $\left(\mathrm{Fe}_{2} \mathrm{O}_{3}\right)$ & 18 \\
\hline Total & $\sim 100$ \\
\hline
\end{tabular}

Table 2 Partial Chemical Composition of Iron Oxide Minerals

\begin{tabular}{||l||c|c|c||}
\hline \multirow{2}{*}{ Element } & \multicolumn{2}{|l||}{$\begin{array}{l}\text { Mineral / Elemental } \\
(\text { wt\% })\end{array}$} & \multicolumn{2}{c||}{ Composition } \\
\cline { 2 - 4 } & Goethite & Hematite & Magnetite \\
\hline \hline Al & 3.53 & 1.45 & 0.12 \\
\hline $\mathbf{C a}$ & 0.03 & 0.10 & 0.95 \\
\hline $\mathbf{F e}$ & 46.3 & 63.50 & 65.00 \\
\hline $\mathbf{M g}$ & 0.20 & 0.03 & 0.58 \\
\hline $\mathbf{M n}$ & 0.20 & 0.04 & 0.075 \\
\hline $\mathbf{S i}$ & 7.81 & 1.13 & 2.23 \\
\hline $\mathbf{T i}$ & 0.23 & 0.03 & 0.02 \\
\hline $\mathbf{S}$ & 0.04 & $<0.01$ & 0.02 \\
\hline
\end{tabular}

The results of the composition of goethite is presented in Table $1 \mathrm{~A}$. It can be seen that the goethite is weathered. It consists of $51 \%$ iron oxide hydroxide, $34 \%$ silica and $12 \%$ hematite as the major constituents. The presence of $\mathrm{SiO}_{2}$ suggests that the sample has undergone some weathering process. Typically, goethite can be formed from the oxidation and hydrolysis of fayalite as indicated in Equation 3 (Cornell and Schwertmann, 2003).

$$
\begin{aligned}
\mathrm{Fe}_{2} \mathrm{SiO}_{4}+1 / 2 \mathrm{O}_{2} & +3 \mathrm{H}_{2} \mathrm{O} \\
& \rightarrow 2 \mathrm{FeOOH}+\mathrm{SiO}_{2} \\
& +2 \mathrm{H}_{2} \mathrm{O}
\end{aligned}
$$

This indicates that goethite will be highly amenable to comminution. Since goethite is an intermediate oxidation product, it is rarely found in nature in the pure form.

The results of the composition of the hematite is presented in Table $1 \mathrm{~B}$. The results show that the hematite is not weathered. Hematite is an end product of iron mineral oxidation, and hence, can be found pure in geo-materials. The formation of hematite may be due to the oxidation of magnetite as shown in Equation 4 (Lemos et al., 2007).

$$
2 \mathrm{Fe}_{3} \mathrm{O}_{4}+1 / 2 \mathrm{O}_{2(\mathrm{~g})} \rightarrow 3 \mathrm{Fe}_{2} \mathrm{O}_{3}
$$

The composition of magnetite is presented in Table 1 C. It can be seen that the sample contains $82 \%$ magnetite and $18 \%$ hematite. The composition suggests that the sample is undergoing weathering according to Equation 4.

The results of the partial chemical composition (Table 2) of the iron oxide minerals confirmed the predominance of iron in all three minerals investigated. The minor elements found were $\mathrm{Si}$ and Al while $\mathrm{Mg}, \mathrm{Mn}, \mathrm{Ca}, \mathrm{Ti}$ and $\mathrm{S}$ were in trace amounts.

\subsection{Specific Surface Area of Iron Oxide Minerals}

The results of the specific surface area for the iron oxide minerals are presented in Table 3 . The specific surface area of the magnetite was $2.79 \mathrm{~m}^{2} / \mathrm{g}$ and that of goethite and hematite were 13.30 and $6.45 \mathrm{~m}^{2} / \mathrm{g}$ respectively (Table 3 ). The high specific surface area of goethite may be due to weathering which may induce micropores. In addition, the specific surface area of iron oxides has been observed to influence their thermodynamic stability and reactivity during interaction with adsorbents (Cornell and Schwertmann, 2003).

Table 3 Specific Surface Area of Iron Oxide Minerals (Adsorption Substrates)

\begin{tabular}{||l|c||}
\hline Iron Oxide Mineral & $\begin{array}{l}\text { Specific Surface } \\
\text { Area }\left(\mathbf{m}^{2} / \mathbf{g}\right)\end{array}$ \\
\hline \hline Goethite $(\mathrm{FeOOH})$ & 13.30 \\
\hline Hematite $\left(\mathrm{Fe}_{2} \mathrm{O}_{3}\right)$ & 6.45 \\
\hline Magnetite $\left(\mathrm{Fe}_{3} \mathrm{O}_{4}\right)$ & 2.79 \\
\hline
\end{tabular}

\subsection{Zeta Potential of Iron Oxide Minerals}

Results of the surface potential trend for goethite, hematite and magnetite as a function of $\mathrm{pH}$ in the presence and absence of arsenic (V) are shown in Figs. 1, 2 and 3 respectively. 


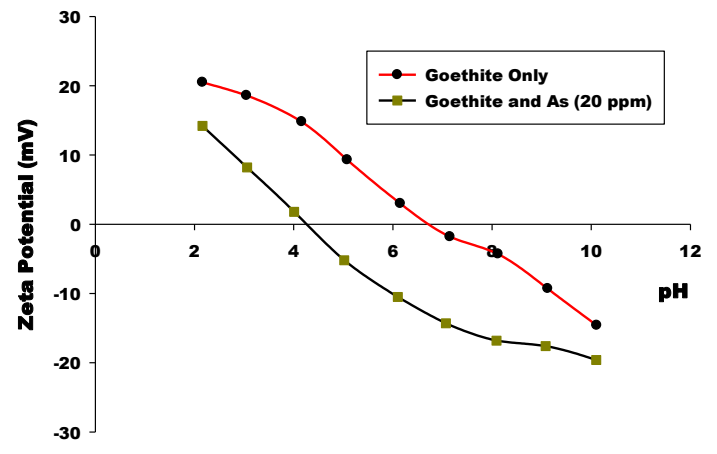

Fig. 1 Zeta Potential of Goethite as a Function of pH with and without Arsenic

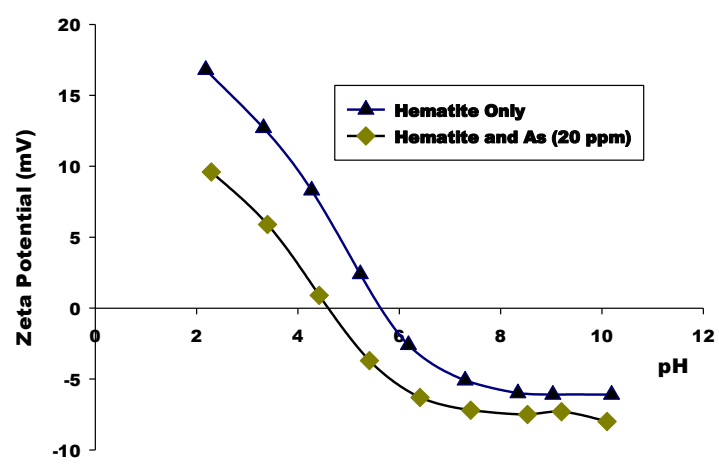

Fig. 2 Zeta Potential of Hematite as a Function of $\mathrm{pH}$ with and without Arsenic

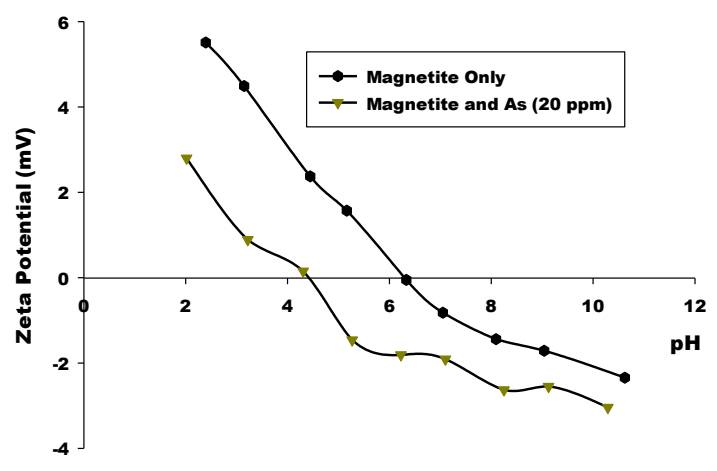

Fig. 3 Zeta Potential of Magnetite as a Function of $\mathrm{pH}$ with and without Arsenic

The results indicate that, in the absence of arsenic, the IEP of goethite is 6.7, which is within the range of values reported in literature (Langmuir, 1997). Upon interaction with arsenic however, the IEP value shifts to 4.2 and the magnitude of the surface charge potential is observed to decrease significantly over the entire $\mathrm{pH}$ range. The IEP value of the hematite in the absence of arsenic was observed to be 5.6, which typically falls within the range of values reported in literature (Langmiur,
1997). Upon arsenic addition, the IEP shifted to 4.6 with a decrease in magnitude of the surface charge over the entire $\mathrm{pH}$ investigated. The IEP of magnetite in the absence of arsenic (V) was at 6.2 which also corresponds well with work done by Ardizzone et al., (1982). This value, however, reduced to 4.4 upon arsenic addition and showed a surface charge decrease over the entire $\mathrm{pH}$ range.

The observed trends described above, can be explained as follows:

During interaction with water, the interfacial charge on the iron oxides is modified (Langmuir, 1997): surface complexes - $\mathrm{FeOH}_{2}^{+}, \mathrm{FeOH}$ and $\mathrm{FeO}^{-}$ (Langmiur, 1997) are formed as shown in Equations 5 and 6 (Cornell and Schwertmann, 2003).

$$
\begin{aligned}
& \mathrm{FeOH}_{2}^{+} \leftrightarrow \mathrm{FeOH}+\mathrm{H}^{+} \\
& \mathrm{FeOH} \leftrightarrow \mathrm{FeO}^{-}+\mathrm{H}^{+}
\end{aligned}
$$

Since these reactions are $\mathrm{pH}$ dependent, the surfaces tend to be positively charged at low $\mathrm{pH}$ where the equilibrium curve will be displaced to the left. As $\mathrm{pH}$ increases, the surfaces deprotonate resulting in negatively charged species which causes a displacement of the equilibrium curve to the right. In solution, arsenic (V) oxyanions exist as anions (including; $\mathrm{H}_{2} \mathrm{AsO}_{4}{ }^{-}, \quad \mathrm{HAsO}_{4}{ }^{{ }^{-}}$and $\mathrm{AsO}_{4}{ }^{3^{-}}$). Therefore, below the IEP's of the substrates (ie. IEP $<5.6$ - 6.7) where the surfaces are positively charged, arsenic adsorption was observed to occur. This is evidenced by a shift of the IEP to the left upon arsenic addition by indicating that there was a strong arsenic attraction towards the iron oxide surface. The zeta potential was therefore observed to decrease significantly indicating that arsenic adsorption results in reduction in interfacial potential, hence, the zeta potential.

Arsenic adsorption onto iron oxide surfaces may be specific or non-specific (Hunter, 1981; Cornell and Schwertmann, 2003; Henke, 2009). Specific adsorption occurs in the inner sphere stern complex where ionic/covalent bonding of chemical species directly onto the surface of the mineral particle is experienced. Specific adsorption is also characterised by a shift of the IEP along the $\mathrm{pH}$ scale to lower $\mathrm{pH}$ values and a reversal of the zeta potential sign (Hunter, 1981; Cornell and Schwertmann, 2003). In the current study, these trends were observed, indicating that arsenic was specifically adsorbed onto the iron oxide surface. A decrease in surface charge over the entire $\mathrm{pH}$ range also indicates that arsenic adsorption onto the iron oxide minerals occurred above $\mathrm{pH}>$ IEP. According to Cornell and Schwertmann (2003); at pH > IEP, $\mathrm{FeO}^{-}$group predominates over $\mathrm{FeOH}^{+}{ }_{2}$ group. This means that although the surface has a net negative charge, some $\mathrm{FeOH}^{+}{ }_{2}$ will still be present to reduce 
the adsorbent's surface potential and therefore enhance the adsorption. This kind of adsorption is of a physical nature and may be due to weak van der Waal forces (Pal, 2015). Furthermore, at $\mathrm{pH}<$ IEP, $\mathrm{FeOH}^{+}{ }_{2}$ group will predominate over $\mathrm{FeO}^{-}$group resulting in a net positive charge. At the IEP, the number of $\mathrm{FeOH}^{+}{ }_{2}$ groups will be equal to $\mathrm{FeO}^{-}$ groups thereby resulting in an overall neutral charge.

\section{Conclusions}

The study showed that the iron oxide minerals were predominantly hematite, magnetite and goethite with goethite containing significant amounts of quartz. The iron oxide minerals were also shown to have different mineralogical and chemical compositions. Consequently, their specific surface areas were different.

The study further indicated that the interfacial properties of the minerals are different and that they play an influential role on arsenic removal from solution. The zeta potential of the iron oxide minerals was strongly positive at $\mathrm{pH} 2$ but indicated a reversal at $\mathrm{pH} \sim>9$. The interactions between iron oxide minerals, arsenic and their hydrolysable products $\left(\mathrm{H}_{2} \mathrm{AsO}_{4}{ }^{-}, \mathrm{HAsO}_{4}{ }^{2^{-}}\right.$and $\left.\mathrm{AsO}_{4}{ }^{{ }^{-}}\right)$, resulted in significant decrease in the magnitude of zeta potential and shifts in IEP of the iron oxide minerals, indicating specific adsorption. The minerals are therefore capable of adsorbing As (V) from solution and that, $\mathrm{pH}$ influences the adsorption. The adsorption is better in acidic medium than basic medium.

\section{Acknowledgements}

Financial support from the Robert S. McNamara Fellowship, World Bank towards this work is highly appreciated. The authors also wish to thank the Future Industries Institute (FII), University of South Australia (UniSA), Australia for their immense support.

\section{References}

Ardizzone, S., Biagiotti, R. and Formaro, L., (1982), "A Re-Examination of the Point of Zero Charge of Magnetite in Aqueous Solutions", Journal of Electroanalytical Chemistry and Interfacial Electrochemistry, Vol. 135, No.1, pp.167-172.

Brunauer, S., Emmett, P.H. and Teller, E., (1938), "Adsorption of Gases in Multimolecular Layers", Journal of the American Chemical Society, Vol. 60, No. 2, pp. 309-319.

Cornell, R. M. and Schwertmann, U., (2003), The iron oxides: Structure, Properties, Reactions,
Occurrences and Uses, John Wiley \& Sons, 659 pp.

Craw, D., Falconer, D. and Youngson, J.H., (2003), "Environmental Arsenopyrite Stability and Dissolution: Theory, Experiment, and Field Observations", Chemical Geology, Vol. 199, No. 1, pp. $71-82$.

Dixit, S. and Hering, J. G., (2003), "Comparison of Arsenic (V) and Arsenic (III) Sorption onto Iron Oxide Minerals: Implications for Arsenic Mobility", Environmental Science \& Technology, Vol. 37, No. 18, pp. 4182-4189.

Fan, L., Zhou, X., Luo, H., Deng, J., Dai, L., Ju, Z., Zhu, Z., Zou, L., Ji, L., Li, B. and Cheng, L., (2016), "Release of Heavy Metals from the Pyrite Tailings of Huangjiagou Pyrite Mine: Batch Experiments", Sustainability, Vol. 8, No. 1, pp. 96 - 109 (1-13).

Faria, M.C., Rosemberg, R.S., Bomfeti, C.A., Monteiro, D.S., Barbosa, F., Oliveira, L.C., Rodriguez, M., Pereira, M.C. and Rodrigues, J.L., (2014), "Arsenic Removal from Contaminated Water by Ultrafine $\delta$-FeOOH adsorbents". Chemical Engineering Journal, 237, pp. 47 - 54.

Feng, L., Cao, M., Ma, X., Zhu, Y. and Hu, C., (2012), "Superparamagnetic high-surface-area $\mathrm{Fe}_{3} \mathrm{O}_{4}$ nanoparticles as adsorbents for arsenic removal", Journal of hazardous materials, 217, pp. 439 - 446.

Giménez, J., Martinez, M., de Pablo, J., Rovira, M. and Duro, L., (2007), "Arsenic Sorption onto Natural Hematite, Magnetite, and Goethite", Journal of Hazardous Materials, Vol. 141, No. 3, pp. 575-580.

Henke, K., (2009), Arsenic: Environmental Chemistry, Health Threats and Waste Treatment, John Wiley \& Sons, Sussex, United Kingdom, $575 \mathrm{pp}$.

Hunter, R.J., (1981), Zeta potential in Colloid Science: Principles and Applications, Vol. 2, Academic Press, Oval Road, London, 398 pp.

Koomson, B. and Asiam, E.K., (2013), "Studies on Arsenic Release and its Mitigation from Tailings Dam Using Nanomagnetite Particles", Ghana Mining Journal, 14, pp.66-69.

Langmuir, B., (1997), Aqueous Environmental Geochemistry, Patience Hall Inc, New Jersey, $600 \mathrm{pp}$.

Lemos, V.P., Costa, M.L.D., Lemos, R.L. and Faria, M.S.G.D., (2007). "Vivianite and Siderite in Lateritic Iron Crust: An Example of Bioreduction", Química Nova, Vol. 30, No. 1, pp.36-40.

Lengke, M.F. and Tempel, R.N., (2005), "Geochemical Modeling of Arsenic Sulfide Oxidation Kinetics in a Mining Environment" Geochimica et Cosmochimica Acta, Vol. 69, No. 2, pp. 341-356. 
Pal, P., (2015), Groundwater Arsenic Remediation:

Treatment Technology and Scale UP, Butterworth-Heinemann, Waltham, USA, 316 pp.

Prucek, R., Tuček, J., Kolařík, J., Filip, J., Marušák, Z., Sharma, V.K. and Zbořil, R., (2013), "Ferrate (VI)-induced arsenite and arsenate removal by in situ structural incorporation into magnetic iron (III) oxide nanoparticles", Environmental science \& technology, Vol. 47, No. 7, pp. 3283 3292.

Raven, K. P., Jain, A. and Loeppert, R. H., (1998), "Arsenite and Arsenate Adsorption on Ferrihydrite: Kinetics, Equilibrium, and Adsorption Envelopes", Environmental Science \& Technology, Vol. 32, No. 3, pp. 344-349.

Shipley, H. J., Yean, S., Kan, A. T. and Tomson, M. B., (2009), "Adsorption of Arsenic to Magnetite Nanoparticles: Effect of Particle Concentration, $\mathrm{pH}$, Ionic Strength, and Temperature", Environmental Toxicology and Chemistry, Vol. 28, No. 3, pp. 509-515.

Walker, F. P., Schreiber, M.E. and Rimstidt, J. D. (2006), "Kinetics of Arsenopyrite Oxidative Dissolution by Oxygen, Geochimica et Cosmochimica Acta, Vol. 70, No. 7, pp. 1668 1676.

Warhurst, A. and Noronha, L., (2000), "Environmental Policy in Mining: Corporate Strategy and Planning for Closure", Lewis Publishers, Washington DC, pp. 118 - 139.

Yavuz, C. T., Mayo, J. T., William, W. Y., Prakash, A., Falkner, J. C., Yean, S., Cong, L., Shipley, H. J., Kan, A., Tomson, M. and Natelson, D., (2006), "Low-Field Magnetic Separation of Monodisperse $\mathrm{Fe}_{3} \mathrm{O}_{4}$ Nanocrystals", Science, Vol. 314, No. 5801, pp. 964-967.

\section{Authors}

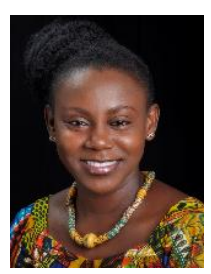

B. Koomson is a lecturer and consulting Engineer at the Department of Materials Engineering, KNUST, Ghana. She holds a $\mathrm{PhD}$, an MPhil and a BSc degree in Minerals Engineering from University of Mines and Technology (UMaT), Tarkwa, and the Kwame Nkrumah University of Science and Technology (KNUST), Kumasi, respectively. She is a member of the Ghana Institute of Engineers (GhIE). Her research interests are; reprocessing of waste materials, nanotechnology, water quality monitoring and waste water treatment.

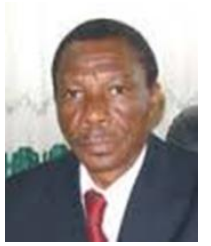

E. K. Asiam is an Associate Professor of Minerals Engineering and an adjunct Professor at the Department of Materials Engineering, KNUST, Ghana. He holds a $\mathrm{PhD}$ and BSc degrees from the Kwame Nkrumah University of Science and Technology (KNUST), Kumasi. He has researched and consulted extensively on processing of refractory gold ores and environmental quality assessment and management. 